\title{
Stable Isotope Dilution Analysis of $N$-Acetylaspartic Acid in CSF, Blood, Urine and Amniotic Fluid: Accurate Postnatal Diagnosis and the Potential for Prenatal Diagnosis of Canavan Disease
}

\author{
C. Jakobs ${ }^{1}$, H. J. Ten Brink ${ }^{1}$, S. A. LangelaAR ${ }^{1}$, T. ZeE ${ }^{1}$, F. Stellaard ${ }^{1}$,

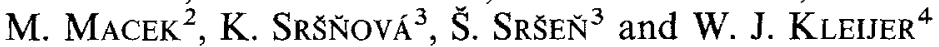 \\ ${ }^{1}$ Department of Pediatrics, Free University Hospital, De Boelelaan 1117, $1081 \mathrm{HV}$ \\ Amsterdam, The Netherlands; ${ }^{2}$ Department of Medical Genetics, Charles University, \\ Prague, Czechoslovakia; ${ }^{3}$ Department of Clinical Genetics, Komensky University, \\ Martin, Czechoslovakia; ${ }^{4}$ Department of Clinical Genetics, Erasmus University, \\ Rotterdam, The Netherlands
}

\begin{abstract}
Summary: A sensitive and selective analytical technique is described for the determination of $\mathrm{N}$-acetylaspartic acid in body fluids using stable isotope dilution in combination with positive chemical ionization mass spectrometry with selected ion monitoring.

Control mean and ranges have been established: in urine 19.5 and 6.6$35.4 \mu \mathrm{mol} / \mathrm{mmol}$ creat.; in plasma 0.44 and $0.17-0.81 \mu \mathrm{mol} / \mathrm{L}$; in cerebrospinal fluid 1.51 and $0.25-2.83 \mu \mathrm{mol} / \mathrm{L}$; and in amniotic fluid 1.27 and $0.30-2.55 \mu \mathrm{mol} / \mathrm{L}$.

In a patient with Canavan disease, $N$-acetylaspartic acid concentration was elevated 80 -fold in urine and 20-fold in plasma compared to the control means. A subsequent pregnancy of the mother was monitored and the $N$-acetylaspartic acid concentration in the amniotic fluid was within the control range and a healthy child was born.
\end{abstract}

\section{INTRODUCTION}

Increased $N$-acetylaspartic acid (NAA) levels in urine, blood and cerebrospinal fluid (CSF) have been reported by Kvittingen et al. (1986) in a patient with cerebellar atrophy and by Hagenfeldt et al. (1987) in a patient with leukodystrophy. The excessive NAA excretion was probably caused by the deficiency of aspartoacylase (EC 3.5.1.15) as was demonstrated by Hagenfeldt et al. (1987) in their patient's fibroblasts. Subsequently Matalon et al. (1988) and Divry et al. (1989) linked Nacetylaspartic aciduria and aspartoacylase deficiency with Canavan disease (Canavan,

MS received 14.5.90 Accepted 11.1.91 
1931) and this finding has since been confirmed in at least 25 patients (Echenne $e t$ al., 1989; Elpeleg et al., 1989; Matalon et al., 1989; Ozand et al., 1990).

Canavan disease (McKusick 27190) is a form of leukodystrophy inherited as an autosomal recessive disease (Buchanan and Davis, 1965; Van Bogaert and Bertrand, 1967). The neurological symptoms usually appear in the first few months of life and are due to demyelinization and leukodystrophy with associated megalencephalopathy, blindness and spasticity. Until recently the definitive diagnosis of Canavan disease required the demonstration of spongy degeneration of white matter in a biopsy or necropsy. The recent finding of $N$-acetylaspartic aciduria in patients with Canavan disease suggests that measurement of urinary NAA provides an easier diagnosis.

As the course of this disease is devastating and treatment is not available, prenatal diagnosis is in demand. For several organic acidurias quantitation of specific metabolites in amniotic fluid is a reliable and fast method for prenatal diagnosis (Sweetman, 1984; Jakobs et al. 1990). We therefore developed a sensitive and accurate stable isotope dilution method for the quantitation of NAA in amniotic fluid. Using this method we have established normal ranges for the concentrations of this compound in CSF, plasma, urine and amniotic fluid, which were hitherto not all available.

A patient with Canavan disease was diagnosed as having $N$-acetylaspartic aciduria and in addition prenatal investigations were performed in a subsequent pregnancy.

\section{CASE REPORT}

In the affected family there is no evidence for consanguinity. However, the ancestors of the parents are from a very small village, so that it is necessary to calculate with the endogamy. In the three-generation genealogy there are no degenerative diseases.

The index case, a girl, was born after an uncomplicated pregnancy and delivery. Birthweight was $2600 \mathrm{~g}$ and length $47 \mathrm{~cm}$. She was normal until the age of 2 months when frequent tonic-clonic seizures up to four times a day were observed. The seizures were unresponsive to antiepileptic drug treatment. From the age of 3 months the girl showed an inversion of her sleep rhythm: she slept during daytime. Impaired psychomotor development became obvious from the age of 4 months. At that time muscle hypertonia was present; the upper extremities were in a flexed position and the lower extremities were in extension. She showed opisthotonus from the age of 9 months. Choreoathethosis was not observed. The girl became severely disabled, deteriorating to a vegative state by the age of 2 years. Severe failure to thrive became obvious. The girl is still alive at 5 years of age.

Ophthalmological examination revealed optic atrophy without retinal abnormalities and preserved pupil reflexes. A complete hearing loss has not been proved by electrophysiological tests.

Electroencephalography recording showed only abnormal background activity with high beta activity.

Skull X-ray showed macrocephaly. A CT scan of the brain at 6 months of age revealed diffuse white matter hypodensity in both hemispheres as well as in the cerebellum, associated with an increased subarachnoidal space. A cerebral cortex 
biopsy was performed at the age of 9 months and showed a marked vacuolization in the subcortical layer of the U-fibres producing a spongy appearance by light microscopy. There was a microspongiosis of the neuroepithelium and clear vacuolization of the perivascular and of the perineuronal glia within the grey mass of the middle layer of the cerebral cortex.

The spongiosis originates from the hydrophobic degeneration of the increased quantity of neuroglia with oxyphilic plasmatic spots characteristic of Canavan disease.

Ultrastructural studies revealed typical increase of dense megaconial mitochondria.

Except for a hypochromic anaemia, no abnormalities were found on routine haematological and biochemical testing. CSF analysis showed normal glucose and cell count, but a constantly increased protein level $(780 \mathrm{mg} / \mathrm{L}$; prealbumin $3.4 \%$, albumin $70.1 \%, \alpha 11.4 \%, \alpha 24.2 \%, \beta 10.5 \%$ and $\gamma 10.5 \%$ ).

Urine organic acids revealed $\mathrm{N}$-acetylaspartic aciduria at the age of 5 years (see results).

During the third pregnancy, prenatal investigation was performed in amniotic fluid and in cultured amniotic fluid cells. The biochemical examinations provided no evidence for an affected fetus. After delivery, the child (girl) demonstrated an uncomplicated neurological development during her first year of life and no other clinical signs of the disease are apparent.

\section{MATERIALS AND METHODS}

Materials: $N$-Acetylaspartic acid was purchased from Sigma Chemical Company, St. Louis MO, USA. [ $\left.\mathrm{D}_{3}\right]-N$-acetylaspartic acid was synthesized as described below. All other chemicals were of analytical grade and used without prior treatment.

Synthesis of $\left[D_{3}\right]$-N-acetylaspartic acid: To an ice-cooled solution of L-aspartic acid $(0.13 \mathrm{~g}, 1 \mathrm{mmol})$ and sodium hydroxide $(0.10 \mathrm{~g}, 2.5 \mathrm{mmol})$ in water $(600 \mathrm{ml})\left[\mathrm{D}_{6}\right]$ acetic anhydride (125 ml, $1.2 \mathrm{mmol}, 99$ atom \% D, Janssen Chimica, Beerse, Belgium) was added, and the solution was shaken for 1 hour with cooling. The reaction mixture was acidified with $\mathrm{HCl}$ to $\mathrm{pH} 1$ and dried in a stream of nitrogen. The residue was extracted with acetone $(20 \mathrm{ml})$, and the dried extract was washed with diethylether to yield [acetyl- $\left.\mathrm{D}_{3}\right]-\mathrm{N}$-acetylaspartic acid $(0.15 \mathrm{~g}, 98 \mathrm{atom} \%)$ as a gum. The product was obtained in a crystalline form by crystallization from ethanol-diethyl ether.

Sample collection: Control urine, plasma and CSF samples were obtained from healthy persons (age 1 week-14 years) who did not have any symptoms of hepatic or neurological disease. Control amniotic fluid samples were obtained in the 16-18th week of pregnancies in which the amniocentesis was performed because of advanced maternal age.

Samples were stored at $-20^{\circ} \mathrm{C}$ prior to the analysis. There has been no effect of sample storage observed during the 2 years of this study.

Sample preparation: An aqueous solution of $\left[\mathrm{D}_{3}\right]-\mathrm{N}$-acetylaspartic acid was added as internal standard to $1.00 \mathrm{ml}$ of a biological sample $(25 \mathrm{nmol} / \mu \mathrm{mol}$ creat. for urine; $5 \mathrm{nmol} / \mathrm{ml}$ for amniotic fluid, and $3 \mathrm{nmol} / \mathrm{ml}$ for plasma and CSF). This was also 
added to an aqueous standard, to obtain a calibration curve in the range from 5 to $100 \mathrm{nmol}$ for urine, 5 to $20 \mathrm{nmol}$ for amniotic fluid, and 0.5 to $5 \mathrm{nmol}$ for plasma and $\mathrm{CSF}$. The sample was acidified with $30 \mu \mathrm{l} \mathrm{HCl}(6 \mathrm{~mol} / \mathrm{L})$ to $\mathrm{pH}<2$ and saturated with sodium chloride. Thereafter the sample was extracted four times with $2 \mathrm{ml}$ of an ethylacetate-2-propanol mixture (v/v 10:1). The collected organic fractions were dried by anhydrous sodium sulphate and subsequently evaporated to dryness at $40^{\circ} \mathrm{C}$ under a gentle stream of nitrogen. The residue was trimethylsilylated with a $50 \mu \mathrm{l}$ MSTFA/pyridine mixture $(1: 1)$. An aliquot of $1 \mu \mathrm{l}$ of this mixture was analysed by gas chromatography-mass spectrometry.

Gas chromatography-mass spectrometry (GC-MS): GC-MS analysis of $\mathrm{N}$-acetylaspartic acid-diTMS was performed on a Kratos MS-80 mass spectrometer (Kratos Ltd, Manchester, UK). The chromatographic separation was achieved on a CPSil19-CB capillary fused silica column; $25 \mathrm{~m} \times 0.32 \mathrm{~mm}$ with $\mathrm{df}=0.48 \mu \mathrm{m}$ (Chrompack Int., Middelburg, The Netherlands) which was directly inserted into the source of the mass spectrometer. Helium was used as carrier gas with a linear flow of $20 \mathrm{~cm} / \mathrm{s}$. A cold on-column injector was used. The oven temperature was kept at $120^{\circ} \mathrm{C}$ for $1 \mathrm{~min}$ and then raised to $250^{\circ} \mathrm{C}$ at a rate of $30^{\circ} \mathrm{C} / \mathrm{min}$. The interface and source temperatures were kept at $250^{\circ} \mathrm{C}$. Mass fragmentography was achieved with positive chemical ionization with ammonia as reagent gas at a source pressure of $2 \times 10^{-4}$ torr. The filament emission current was $1.5 \mathrm{~mA}$ and the electron energy was set at $40 \mathrm{eV}$. The ions $m / z 320.19$ (base peak protonated pseudomolecular ion $(M+1)$ for $N$-acetylaspartic acid-diTMS) and $m / z 323.21$ (base peak $(M+1)$ for $\left[\mathrm{D}_{3}\right]-N$ acetylaspartic acid-diTMS) were monitored with a $50 \mathrm{~ms}$ dwell time in the selected ion monitoring (SIM) mode at a resolution of 1000 (10\% valley). The areas of the mass fragmentographic peaks were calculated by means of an operator-controlled data system. Mass spectra of authentic standards were obtained by scanning over the mass range of $m / z 50-600$ with a 3-s scan time.

Enzyme analysis: Confluent cultures of skin fibroblasts and amniotic fluid cells were grown according to routine procedures and were harvested by trypsinization 7 days after the previous subculture. Cells were washed in saline, homogenized by sonification in $3 \%$ Triton X-100 in water and centrifuged for $10 \mathrm{~min}$ at $10000 \mathrm{~g}$. Aspartoacylase activity was assayed in the supernatant as described by Matalon et al. (1988).

\section{RESULTS}

Gas chromatography-mass spectrometry: Electron impact (EI) ionization of the diTMS derivatives of NAA gave considerable fragmentation and hence a rather low intensity of the molecular ion, and even the ion at $m / z$ of $M-15$ due to loss of a methyl group was only $7.6 \%$ of the base peak at $m / z=73$.

Chemical ionization $(\mathrm{CI})$ with ammonia gave much less fragmentation and the base peak in the spectra of NAA-diTMS and $\left[\mathrm{D}_{3}\right]$-NAA-diTMS were the protonated pseudomolecular ions $(M+1)$ (Figure 1a and $1 \mathrm{~b}$ ). Therefore the protonated pseudomolecular ions were determined in the SIM mode at $\mathrm{m} / \mathrm{z} 320$ for NAA-diTMS and $m / z 323$ for $\left[\mathrm{D}_{3}\right]$-NAA-diTMS. 
(a)

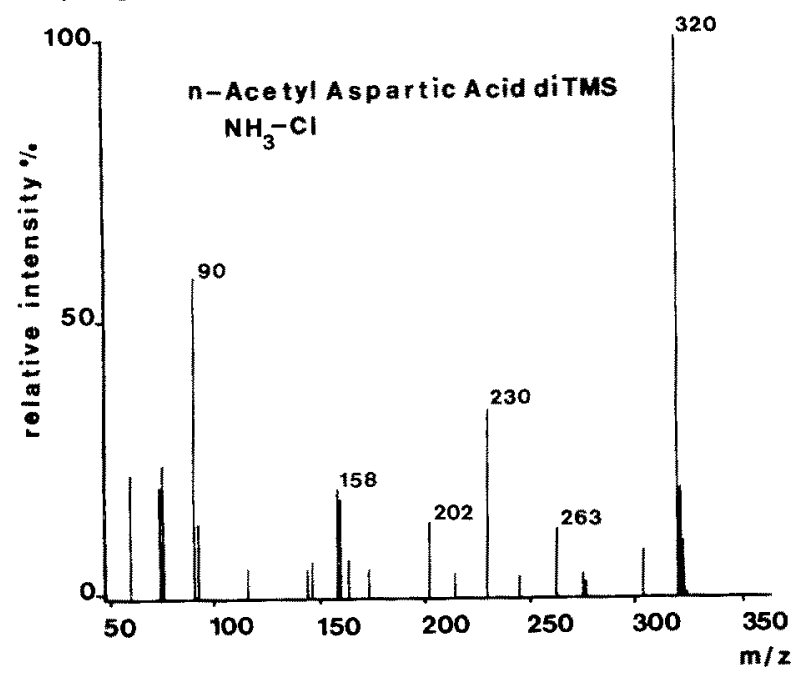

(b)

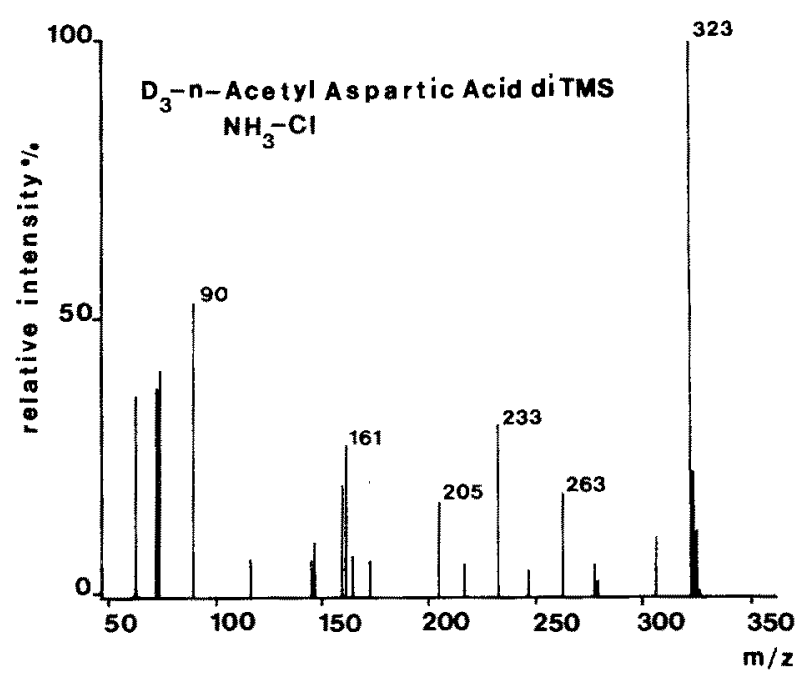

Figure 1 (a) Ammonia chemical ionization mass spectrum of the di-TMS derivative of $\mathrm{N}$ acetylaspartic acid. (b) Ammonia chemical ionization mass spectrum of the di-TMS derivative of $\left[\mathrm{D}_{3}\right]$ - $N$-acetylaspartic acid.

The actual limit of detection was $0.2 \mu \mathrm{mol} / \mathrm{L}$ for EI ionization, whereas we obtained $0.02 \mu \mathrm{mol} / \mathrm{L}$ by using $\mathrm{Cr}$ ionization.

Quantitative data: The standard calibration curve yielded straight lines that went through the origin. Linear regression analysis was used to calculate the concentration of NAA in the biological samples. Table 1 shows the concentrations of NAA in CSF, plasma and urine of control individuals (age 1 week-14 years), the index case with $\mathrm{N}$-acetylaspartic aciduria and her healthy sibling, together with the results of the aspartoacylase assays. There was no age dependency of the control NAA concentra- 
Table 1 Concentrations of $\mathrm{N}$-acetylaspartic acid in various body fluids and the aspartoacylase activity in cultured fibroblasts of the index case, the healthy newborn and controls

\begin{tabular}{lcccc}
\hline & \multicolumn{2}{c}{$\mathrm{N}$-Acetylaspartic acid } & Aspartoacylase in \\
\cline { 2 - 4 } & $\begin{array}{c}\text { Urine } \\
\text { fibroblasts }\end{array}$ & $\begin{array}{c}\text { Plasma } \\
(\mu \mathrm{mol} / \mathrm{mm})\end{array}$ & $\begin{array}{c}\text { CSF } \\
(\mu \mathrm{mol} / \mathrm{L})\end{array}$ & $\begin{array}{c}\text { (nmol creat. }) \\
\left(\mathrm{nmol}^{-1} \mathrm{~h}^{-1}(\mathrm{mg} \text { protein })^{-1}\right)\end{array}$ \\
\hline Index case & 1491 & 9.32 & n.d. & 0.0 \\
Newborn child & 10.0 & n.d. & n.d. & n.d. \\
Controls & $(n=25)$ & $(n=25)$ & $(n=14)$ & $(n=23)$ \\
Mean & $19.5 \pm 10.3$ & $0.44 \pm 0.20$ & $1.51 \pm 0.89$ & $16.8 \pm 7.9$ \\
Range & $6.6-35.4$ & $0.17-0.84$ & $0.25-2.83$ & $6.0-29.4$ \\
\hline
\end{tabular}

n.d. $=$ not determined

tions in urine and plasma. NAA levels in urine, plasma and CSF of the patient were elevated 80 -fold and 20-fold respectively compared to the control means. Aspartoacylase activity was absent in the patient's fibroblasts.

Table 2 shows the NAA concentrations in amniotic fluid of controls and the pregnancy at risk, together with the enzymatic data in amniotic fluid cells. NAA levels in the control amniotic fluid samples are accurately measurable; the level in the pregnancy at risk was found to be in the control range. Aspartoacylase activity in amniotic fluid cells was considerably lower than in cultured skin fibroblasts. In some controls the activity in amniocytes approached the lower limit of reliable determinations; this was also the case for the cells from the pregnancy at risk.

\section{DISCUSSION}

In the isotope dilution assay the $\left[\mathrm{D}_{3}\right]$-NAA serves as a carrier as well as the ideal internal standard for quantitation. It protects against the loss of small amounts of endogenous NAA during the entire procedure.

The chemical ionization technique increased the sensitivity and therefore the stable isotope dilution GC-MS CI mass fragmentographic detection allows highly sensitive, specific and accurate measurements. Although NAA recovery in the solvent extraction procedure is low and variable, the introduction of the labelled internal standard circumvents this problem.

Table 2 Concentrations of $\mathrm{N}$-acetylaspartic acid in amniotic fluid and aspartoacylase activity in amniotic fluid cells of the pregnancy at risk and controls

\begin{tabular}{lcc}
\hline & $\begin{array}{c}\mathrm{N} \text {-acetylaspartic acid in } \\
\text { amniotic fluid } \\
(\mu \mathrm{mol} / \mathrm{L})\end{array}$ & $\begin{array}{c}\text { Aspartoacylase in } \\
\text { amniotic fluid cells } \\
\left.\left(\mathrm{nmol} \mathrm{h}^{-1} \text { (mg protein }\right)^{-1}\right)\end{array}$ \\
\hline $\begin{array}{l}\text { At-risk pregnancy } \\
\text { Controls }(n=10)\end{array}$ & 1.82 & 0.29 \\
$\quad$ mean & $1.27 \pm 0.74$ & $1.3 \pm 1.1$ \\
range & $0.30-2.55$ & $0.32-3.4$ \\
\hline
\end{tabular}


This method has enabled us to establish reference ranges of NAA concentrations in CSF, plasma, urine and amniotic fluid. NAA appears to be a normal constituent in the body fluids rather than a unique metabolite restricted to pathological states. Therefore the distinction between normal and pathological states requires quantitative assessment of NAA levels. Although synthesis of NAA has not been reported in any organ other than the central nervous system (Kvittingen et al, 1986), very low concentrations are normally found in CSF and plasma. The high concentration of NAA in neurons is probably very efficiently kept within the cells (Kvittingen et al., 1986; Hagenfeldt et al., 1987).

The high level of NAA in CSF of patients and the concentration gradient from CSF to plasma indicates that indeed the brain is the source of NAA. The high levels in urine must be due to efficient excretion by glomerular filtration.

In accordance with the previous reports on Canavan disease we found in the present patient greatly elevated concentrations of NAA in urine and plasma and a clear deficiency of aspartoacylase activity in skin fibroblasts. This confirmed the feasibility of biochemical diagnosis of Canavan disease and suggested the use of similar methods for prenatal diagnosis. However, in amniotic fluid cells the aspartoacylase activity appeared to be considerably lower than in skin fibroblasts, which severely hampers the accuracy of measurements at the lower limit of the range.

The low aspartoacylase activity in the investigated at-risk pregnancy did not, therefore, allow a definite diagnosis. Further studies of amniotic fluid cells and chorionic villi and improvement of the enzyme assay will be needed to provide reliable prenatal diagnosis by this approach in all cases.

The NAA level detected by GC-MS with SIM in amniotic fluid from the pregnancy at risk was within the normal range, which suggested an unaffected fetus; the pregnancy was continued and the now 1-year-old child is healthy.

It remains to be established whether the NAA level in an affected pregnancy at 16 weeks is indeed increased. The present sensitive stable isotope dilution method should detect any significant elevation in amniotic fluid even if this would be far less than in urine of patients with Canavan disease.

\section{ACKNOWLEDGEMENTS}

We thank $\mathrm{Mr} \mathrm{H}$. C. Janse for his investigations of the aspartoacylase activity.

We are grateful to Prof. dr. A. Jirišek, First Institute of Pathological Anatomy, First Medical Faculty, Charles University, Prague, for providing us with the detailed information on the brain biopsy.

\section{REFERENCES}

Buchanan, D. S. and Davis, R. L. Spongy degeneration of the nervous system: a report of 4 cases with a review of the literature. Neurology 15 (1965) 207-222

Canavan, M. M. Schilder's encephalites peri-axialis diffusa. Report of a case in a child aged sixteen and one-half months. Arch. Neurol. Psychiatry (Chicago) 25 (1931) 299-308

Divry, P., Vianey-Liaud, C., Gay, C., Macabeo, V., Rapin, F. and Echenne, B. N-Acetylaspartic aciduria; report of three new cases in children with a neurological syndrome associating macrocephaly and leukodystrophy. $J$. Inher. Metab. Dis. 11 (1988) 307-308 
Echenne, B., Divry, P. and Vianey-Liaud, C. Spongy degeneration of the neuraxis (CanavanVan Bogaert Disease) and $N$-acetylaspartic aciduria. Neuropediatrics 20 (1989) 79-81

Elpeleg, O. N., Amir, N., Barash, V., Glick, B., Gross-Tsur, V., Shachar, E., Shapira, Y. and Tzelnik, N. Canavan disease and $N$-acetylaspartic aciduria. Neuropediatrics 20 (1989) 238

Hagenfeldt, L., Bollgren, I. and Venizelos, N. N-Acetylaspartic aciduria due to aspartoacylase deficiency - a new aetiology of childhood leukodystrophy. J. Inher. Metab. Dis. 10 (1987) $135-141$

Jakobs, C., Ten Brink, H. J. and Stellaard, F. Prenatal diagnosis of inherited metabolic disorders by quantitation of characteristic metabolites in amniotic fluid: Facts and future. Prenat. Diag. 10 (1990) 265-271

Kvittingen, E. A., Guldal, G., Borsing, S., Skalpe, I. O., Stokke, O. and Jellum, E. NAcetylaspartic aciduria in a child with a progressive cerebral atrophy. Clin. Chim. Acta 158 (1986) $217-227$

Matalon, R., Michals, K. M., Sebesta, D., Deanching, M., Gashkoff, P. and Casanova, J. Aspartoacylase deficiency and $N$-acetylaspartic aciduria in patients with Canavan Disease. Am. J. Hum. Gen. 29 (1988) 463-471

Matalon, R., Kaul, R., Casanova, J., Michals, K., Johnson, A., Rapin, I., Gashkoff, P. and Deanching, M. Aspartoacylase deficiency: the enzyme defect in Canavan Disease. $J$. Inher. Metab. Dis. 12 (1989) 329-331

Ozand, P. T., Gascon, G. G. and Dhalla, M. Aspartoacylase deficiency and Canavan Disease in Saudi Arabia. Am. J. Med. Gen. 35 (1990) 266-268

Sweetman, L. Prenatal diagnosis of the organic acidurias. J. Inher. Metab. Dis. 7 (Suppl. 1) (1984) $18-22$

Van Bogaert, L. and Bertrand, I. Spongy Degeneration of Brain in Infancy, North Holland Publishing Co., Amsterdam, 1967, pp. 3-132 